\title{
Knowledge of AIDS and HIV risk-related sexual behavior among Nigerian naval personnel Ugboga Adaji Nwokoji ${ }^{1}$ and Ademola J Ajuwon*2
}

\author{
Address: ${ }^{1}$ Nigerian Red Cross Society, National Headquarters, 11, Eko Akete Close, Off St. Gregory Street, South West Ikoyi, Lagos Nigeria and \\ 2Department of Health Promotion and Education, College of Medicine, University of Ibadan, Ibadan, Nigeria \\ Email: Ugboga Adaji Nwokoji - unwoo@yahoo.com; Ademola J Ajuwon* - ajajuwon@yahoo.com \\ * Corresponding author
}

Published: 21 June 2004

BMC Public Health 2004, 4:24 doi: 10.1 I86/147/-2458-4-24
Received: 21 February 2004

Accepted: 21 June 2004

This article is available from: http://www.biomedcentral.com/I47I-2458/4/24

(C) 2004 Nwokoji and Ajuwon; licensee BioMed Central Ltd. This is an Open Access article: verbatim copying and redistribution of this article are permitted in all media for any purpose, provided this notice is preserved along with the article's original URL.

\begin{abstract}
Background: The epidemic of HIV continues to grow in Nigeria. Personnel in the military are at increased risk of HIV infection. Although HIV-risk related sexual behavior of Nigerian police officers has been studied, little is known about the sexual behavior of their counterparts in the Navy. This study describes knowledge of AIDS, and HIV-risk sexual behavior of naval personnel in Lagos Nigeria.
\end{abstract}

Methods: Four hundred and eighty personnel of the Nigerian Navy completed a 70-item questionnaire in 2002. Group discussion and in-depth interviews of four key informants were also conducted to gain insights into the context of risky sexual behaviors and suggestions for feasible HIV primary prevention interventions.

Results: The mean age of the respondents was 34 years. Although the overall mean AIDS knowledge score was 7.1 of 10 points, $52.1 \%$ of respondents believed that a cure for AIDS was available in Nigeria and that one can get HIV by sharing personal items with an infected person (25.3\%). The majority (88. I\%) had had lifetime multiple partners ranging from I-40 with a mean of 5.I; $32.5 \%$ of male respondents had had sexual contact with a female sex worker, $19.9 \%$ did so during the six months preceding the survey. Forty-one percent of those with sexual contact with a female sex worker did not use a condom during the most recent sexual encounter with these women. Naval personnel who have been transferred abroad reported significantly more risky sexual behaviors than others. Group discussants and key informants believed that sex with multiple partners is a tradition that has persisted in the navy even in the era of AIDS because of the belief that AIDS affects only foreigners, that use of traditional medicine provides protection against HIV infection, and influence of alcohol.

Conclusion: Many naval personnel report participating in high-risk sexual behavior which may increase their risk of acquiring and spreading HIV. Naval personnel live and interact freely with civilian population and are potential bridging group for disseminating HIV into the larger population. Interventions including sustained educational program, promotion of condoms, changes in transfer policies are recommended to address this problem. 


\section{Background}

The epidemic of HIV continues to grow in Nigeria despite efforts to control it. Sentinel surveillance among antenatal clinic attendees increased from $1.8 \%$ in 1991 to $5.8 \%$ in 2001 [1,2]. In 2001, 170,000 AIDS-related deaths were reported in the country [3]. With an estimated $5.8 \%$ of adults or 3.5 million persons already infected, Nigeria is now placed fourth among countries with the highest number of HIV infected persons worldwide [4]. HIV/AIDS is a huge burden on the nation's health care system, yet the figures probably underestimate the real magnitude of the epidemic because of underreporting, inadequate resources for HIV testing and missed diagnoses [1,5]. Although the majority of Nigerians are familiar with HIV/ AIDS, risky practices are widespread in young persons [6,7] female sex workers (FSW) [8] and commercial drivers [9], indicating the need for improved intervention programs in these populations.

Primary prevention interventions targeted at vulnerable populations is one of the most realistic strategies for controlling further spread of HIV in the country. In Nigeria as elsewhere, personnel in the military are an important target for primary prevention interventions because they have a high risk of exposure to sexually transmitted infections (STI) including HIV. In peacetime, STI infection rates among armed forces are generally 2 to 5 times higher than in comparable civilian populations and are even greater in times of conflict [10]. AIDS is now the leading cause of death in military and police forces in some African countries, accounting for more than half of in-service mortality $[11,12]$. Figures from Cameroon, Uganda, and Central Africa Republic, show that HIV infection rates in the military and uniformed populations have exceeded rates in the civilian population $[13,14]$. For example, in 1993 Cameroon reported HIV rates of $6.2 \%$ in the military compared to $2 \%$ in the general population [15]. In Uganda, the national HIV prevalence rate was 8.3 in 1999 and $27 \%$ among the military in 1996 [16].

Several factors place men and women in military services at increased risk of HIV infection. First, most military personnel are in the age group at greatest risk of HIV infection namely the sexually active $15-24$ years age group. Second, these predominantly young persons are typically posted to locations away from their homes and families for extended periods of time. Freed from the strictures of their normal social environments many engage in risk behaviors as a means of relieving the tension of loneliness [10], including use of drugs and unprotected sex with FSW $[11,17,18]$. Finally, military professional spirit tends to excuse or even encourage risk taking such as having unprotected sex with multiple partners. The high value placed on aggressiveness in the military makes soldiers prone to pursuing sex with different partners as a type of conquest [10].

In Nigeria, the military rank third among different population groups with high levels of HIV infection [19]. Despite high levels of infection, few studies have been conducted to explore the context in which risky behaviors occur and the conditions which favor these behaviors among military personnel in Nigeria $[15,18]$. This article presents data from a study of personnel in the Nigerian Navy (NN) in Lagos, southwestern Nigeria. The objectives were to assess knowledge of HIV/AIDS and to explore risky sexual behaviors in order to plan appropriate primary prevention interventions.

\section{Methods}

This study was a cross-sectional survey of knowledge of AIDS, sexual practices and perceived susceptibility to HIV infection among naval personnel. This survey was supplemented with qualitative methods which were conducted to gain insights into the context in which risky sexual activities occur and suggestions for feasible interventions in this population. The study population were officers and ratings of the NN. In the Nigerian Navy terminology, personnel below commissioned officers are referred to as ratings. The NN has 10,000 personnel, consisting of 2,000 officers and 8,000 ratings [15].

Lagos, the setting for the study, has a population of 9 million, is Nigeria's most populous city and the country's major commercial center. Lagos has the largest seaport, located on the Atlantic Ocean in the south western part of the country. The NN has three bases in the country located in Lagos in south-west, Warri in mid-west and Port-Harcourt in south-south. The study site was the south-western naval command which has ship and shore establishments in different locations in Lagos.

\section{The survey}

Approval for the study was obtained from the commander of the Lagos base of the navy. The study population was stratified into the four existing departments within the command. These departments are fairly comparable with respect to the composition of staff working in them. Two of these establishments were randomly selected. The list of personnel on board the ships and those on shore in these establishments was used to randomly select personnel from all ranks (ratings and officers) of the navy. Of the 5,000 personnel in the Lagos commend, 600 or $12 \%$ were randomly selected. The first author (UAN), assisted by a trained interviewer, approached each potential respondent, explained the purpose of the study, stated that participation in it was voluntary, and gave out a questionnaire with a brief explanation of how to complete it. In addition, each respondent was provided an assurance of 
Table I: Demographic characteristics, sexual-risk behavior and perception of risk to HIV infection among naval personnel in Lagos, Nigeria $(\mathbf{N}=\mathbf{4 8 0})$

\begin{tabular}{|c|c|c|}
\hline Variable & No & $\%$ \\
\hline \multicolumn{3}{|l|}{ Age group (years) } \\
\hline $15-24$ & 88 & 18.3 \\
\hline $25-34$ & 127 & 26.4 \\
\hline $35-44$ & 212 & 44.1 \\
\hline $45-54$ & 47 & 10.0 \\
\hline$>55$ & 6 & 1.2 \\
\hline \multicolumn{3}{|l|}{ Marital status } \\
\hline Single, never married & 167 & 34.8 \\
\hline Married & 305 & 63.5 \\
\hline Divorced/widowed/separated & 8 & 1.6 \\
\hline \multicolumn{3}{|l|}{ Years of education } \\
\hline Primary & 10 & 2.1 \\
\hline Secondary & 211 & 44.0 \\
\hline Post secondary & 81 & 16.9 \\
\hline Bachelors/post graduate & 145 & 32.3 \\
\hline Others* & 23 & 4.8 \\
\hline \multicolumn{3}{|l|}{ Religion } \\
\hline Christianity & 389 & 81.0 \\
\hline Islam & 87 & 18.1 \\
\hline Traditional & 4 & 0.8 \\
\hline \multicolumn{3}{|l|}{ Current status } \\
\hline Ratings & 361 & 75.2 \\
\hline Officers & 119 & 24.8 \\
\hline \multicolumn{3}{|l|}{ Years in service $(N=474)$} \\
\hline $\mathrm{I}-5$ & 125 & 28.2 \\
\hline $6-10$ & 39 & 8.1 \\
\hline $11-15$ & 83 & 17.3 \\
\hline$>15$ & 227 & 47.7 \\
\hline NA & 6 & 1.3 \\
\hline \multicolumn{3}{|l|}{ History of transfer } \\
\hline Ever been transferred & 439 & 91.8 \\
\hline Ever posted abroad** & 100 & 28.2 \\
\hline \multicolumn{3}{|l|}{ Frequency of transfers } \\
\hline $1-5$ & 265 & 60.9 \\
\hline $6-10$ & 121 & 27.8 \\
\hline$>11$ & 32 & 7.4 \\
\hline NA & 17 & 4.0 \\
\hline Accompanied by spouse during last transfer & 66 & 15 \\
\hline \multicolumn{3}{|l|}{ Pattern of risky sexual behavior } \\
\hline Had multiple partners & 409 & 88.1 \\
\hline Ever had sex with a female sex worker & 156 & 32.5 \\
\hline Had sex with sex worker in last 6 months & 31 & 19.9 \\
\hline Used a condom during last sex with a sex worker & 93 & 59 \\
\hline
\end{tabular}

* These include certificate in military training; ** posting abroad for training, peace keeping

confidentiality of information he or she provides in the questionnaire. Informed consent was implied by voluntary return of the questionnaires. Of the 600 questionnaires distributed, 480 (response rate $80 \%$ ) were returned and used for the analysis. However, there is no data on the profile of respondents who did not return their questionnaires.

Data for the survey were collected in March of 2002 through the administration of a 70-item anonymous questionnaire using a combination of open-and closedended questions. This instrument built upon previously tested questionnaires on HIV/AIDS among female apprentices [7] and male commercial drivers [9] in Nigeria. The questionnaire was divided into five sections for ease of administration, namely demographic characteristics, work conditions including years in service, history of transfers, knowledge about HIV/AIDS, sexual behavior and perceived susceptibility to HIV infection. Knowledge of HIV/AIDS was assessed by requesting 
Table 2: HIVIAIDS knowledge among naval personnel in Lagos, Nigeria $(\mathbf{N}=\mathbf{4 8 0})$

\begin{tabular}{ll}
\hline Statement & Percent answering correctly \\
\hline I. One can get HIV through shaking of hands with an infected person & 91.3 \\
2. One can get HIV through blood transfusion & 96.3 \\
3. One can get HIV by sharing utensils (plates, cups spoons with an infected person) & 87.5 \\
4. One can get HIV by sharing towels, pants, under wears & 74.7 \\
5. One can get HIV by having sexual intercourse with an infected person & 97.7 \\
6. A child can get infected with HIV through breast feeding & 60.4 \\
7. One can get HIV through the use of contaminated instruments like syringes, clippers, blades & 94.6 \\
8. One can get HIV by having sex with many sex partners & 86.9 \\
9. One can get HIV as a punishment for past misdeeds & 71.9 \\
10. A cure for AIDS is now available in Nigeria & 52.1 \\
Mean number of items correctly answered & 7.1 \\
Possible range of scale & $0-10$
\end{tabular}

respondents to determine which of 10 AIDS-related statements was "True" or "False" (Table 2). Prior to its administration, a draft of the questionnaire was pre-tested among 25 naval personnel in the Port-Harcourt base to confirm clarity and comprehension.

\section{Qualitative component}

A preliminary interpretation of the survey data showed the need for in-depth probing on the context in which risky sexual behavior occur in this population. This led to the development of the qualitative component of the study. Focus group discussion (FGD) and key informant interviews were conducted to gain insight into the context in which naval personnel participate in risky sexual behaviors and identify suggestions for feasible interventions to address them. Although eight male officers were invited for the FGD, only four consented to participate. Two of the FGD participants were men who had just returned from a foreign posting. The discussion was conducted in the home of one FGD participant. Snacks and drinks were provided during the discussions, which lasted approximately 50 minutes and were recorded on audiotapes. The first author moderated the discussion in English using a six-item discussion guide. Four officers including two female nurses and two male non-health workers served as key informants. The selection of these personnel was by convenience. The same issues covered during group discussions were explored during interviews.

\section{Data analysis}

The completed questionnaires were checked for completeness and open-ended questions were coded. The data was analyzed with Epi-Info software package, version 6.0, developed by the United States Center for Disease Prevention and Control, Atlanta, Georgia. AIDS knowledge was analysed by assigning one mark to each correct answer provided by the respondents. This was used to generate a 10-point AIDS-Knowledge score. The tapes for the discussion and interviews were transcribed and themes were developed for the analysis.

\section{Results \\ Demographic profile and work conditions}

The ages of the respondents ranged from 18 to 66 years with a mean of 34 years (SD 8.3). The largest percentage $(41.1 \%)$ belonged to the 35-44 years age group (Table 1 ). Virtually all the respondents were males (94.4\%) and most $(63.5 \%)$ were married. Forty four percent had secondary school education and $81 \%$ were Christians. The majority of the respondents (75.2\%) are ratings, $24.8 \%$ are officers. The respondents' military service ranged from one to thirty-three years with a mean of 13.4 years. Among those ever-transferred, the number of transfers ranged from 1 to 25 times with a mean of 4.5 times. At the time of the study only $9.7 \%$ of the respondents had never been transferred, $91.3 \%$ had experienced at least one transfer. Of these, three-fourth (75.4\%) had been transferred up to 8 times. Only $15 \%$ of the transferred respondents traveled with their spouses to the most recent posting site. The major reasons for leaving spouses behind were lack of accommodation, service exigencies (sea operations, courses or military training, peacekeeping operations) and spouse's own job commitment. Of those who had been transferred, 28.2\% were posted to United Kingdom, India, Germany, United States of America, and Ghana for training and to Liberia, Sierra Leone and Congo for peace keeping. The mean duration of period of the time spent abroad was 11.5 months.

\section{Knowledge of HIVIAIDS}

Virtually all (99.4\%) the respondents had heard about AIDS. The respondents' answers to the $10 \mathrm{HIV} / \mathrm{AIDS}$ knowledge questions are shown in Table 2. The overall mean knowledge score was 7.1 of 10 points. The majority (97.7\%) knew that HIV could be transmitted through sex- 
Table 3: Pattern of risky sexual practices among Nigerian naval personnel in Lagos, Nigeria

\begin{tabular}{|c|c|c|c|c|c|}
\hline \multirow{3}{*}{$\begin{array}{l}\text { Variable } \\
\text { Marital status }\end{array}$} & & \multicolumn{3}{|c|}{ Ever had sex with a female sex worker } & \multirow[t]{2}{*}{$P=$ value } \\
\hline & & Yes & & Jo & \\
\hline & No & (\%) & No & (\%) & \\
\hline Single & 45 & $(31.5)$ & 98 & $(68.5)$ & 0.466 \\
\hline Married & 108 & $(36.7)$ & 186 & $(63.3)$ & \\
\hline Others & 3 & $(67)$ & 5 & (33) & \\
\hline \multicolumn{6}{|l|}{ Status } \\
\hline Rating & 101 & $(32.4)$ & 211 & $(67.6)$ & 0.221 \\
\hline Officers & 43 & $(39.4)$ & 66 & $(60.6)$ & \\
\hline \multicolumn{6}{|c|}{ Age group (in years) } \\
\hline $15-24$ & 16 & $(20.8)$ & 61 & (79.2) & $0.012^{*}$ \\
\hline $25-34$ & 36 & $(31.9)$ & 77 & $(68.1)$ & \\
\hline $35-44$ & 79 & $(38.7)$ & 125 & $(61.3)$ & \\
\hline 45 and above & 24 & $(48.9)$ & 25 & $(51.1)$ & \\
\hline \multicolumn{6}{|l|}{ Years in service } \\
\hline $1-5$ & 24 & $(22.6)$ & 82 & (77.4) & $0.018^{*}$ \\
\hline $6-10$ & 16 & $(43.2)$ & 21 & $(56.8)$ & \\
\hline $11-15$ & 23 & $(30.3)$ & 53 & $(67.3)$ & \\
\hline$>15$ & 51 & $(37.2)$ & 56 & $(62.8)$ & \\
\hline
\end{tabular}

* These are significant

ual intercourse with infected persons, blood transfusion $(96.3 \%)$ and by sharing contaminated skin-piercing instruments with infected persons (94.6\%). On the other hand, 52.1\% believed that a cure is available for AIDS in Nigeria and that one can get HIV by sharing personal items such as clothes (25.2\%). About 40\% did not know that HIV can be transmitted through breast feeding.

\section{Sexual behavior and risk-perception}

Virtually all (96.7\%) the respondents had had sex. Threequarters $(75 \%)$ had experienced their first sexual contact by the age of 20 years. The majority $(88.1 \%)$ of the respondents had had multiple sexual partners, with lifetime number of partners ranging from 1 to 40 with a mean of 5.1. During the six months preceding the study, $54.9 \%$ of the respondents had one sexual partner, $25.8 \%$ had no partner and $19.3 \%$ had multiple partners.

Slightly more than a third of male respondents (32.5\%) reported that they had ever had sexual contact with a FSW, $60.2 \%$ had not, but $7.3 \%$ did not answer this question. Of the 156 who had sex with a FSW, $19.9 \%$ did so in the six months preceding the survey. Although more married respondents $(36.7 \%)$ than single ones $(31.5 \%)$ reported ever having had sex with a FSW, the difference was not significant $(\mathrm{p}>0.05)$. Similarly, more officers $(39.4 \%)$ than ratings $(32.4 \%)$ had had sex with a FSW, the difference was not significant ( $\mathrm{p}>0.05$ ). However, older respondents (aged 45 years and above) reported significantly more sexual contacts with FSW than others ( $\mathrm{p}<0.05)$ (Table 3). Overall, the frequency of sexual contact with
FSW during the six months preceding the survey ranged from $1-5$ times; $32.1 \%$ had done so once, $25 \%$ two times, $16 \%$ three times and $10 \%$ four times. Their main reasons were the need to relief sexual tension because regular partner was not available and being under the influence of alcohol.

More than half (59\%) of the 156 respondents who had ever had sex with a FSW reportedly used a condom during their last contact, $41 \%$ did not. Greater proportion of single respondents $(42.2 \%)$ than married ones $(10.2 \%)$ significantly used a condom during their most recent sexual contact with a FSW $(\mathrm{p}<0.05)$. Although more officers $(25.6 \%)$ than ratings (17.8\%) used a condom during their last sexual encounter, the difference was not significant ( $p$ $>0.05)$. Those who did not use a condom with a FSW offered seven reasons for not doing so including belief that they were not susceptible to HIV infection (36.1\%), sex was not planned (17.5\%), dislike for condom (17.5\%), lack of knowledge about AIDS (10.3\%), condom was not available (7.7\%), need for full satisfaction $(5.1 \%)$ and the fact that FSW was a regular partner $(5.2 \%)$.

Overall, more respondents who had ever been transferred locally or abroad (85.2\%), reported having sex with a FSW than those who had not $(23.2 \%)$. In order to explore the relationship between transfers and risky sexual behaviors, we performed a bivariate analysis between personnel who have been posted abroad and their counterparts who had been transferred locally. The results are shown in Table 4. 
Table 4: Comparison of risky sexual behavior among Nigerian naval personnel who had experienced transfers

\begin{tabular}{|c|c|c|c|}
\hline Variable & Posted abroad $(\mathrm{N}=118)$ & Local transfer $(\mathrm{N}=273)$ & $P$ value \\
\hline Had ever had sex with a female sex worker & $52(39.1 \%)$ & $81(32.8 \%)$ & $0.030 *$ \\
\hline Had sex with a sex worker in 6 months preceding survey & $6(25 \%)$ & $18(22.2 \%)$ & $0.027^{*}$ \\
\hline Did not use a condom during last sexual encounter with a sex worker & $22(42.3 \%)$ & $4 \mathrm{I}(52 \%)$ & $0.027^{*}$ \\
\hline Had sex with multiple partners ( 2 or more persons) & $62(52.2 \%)$ & $100(36.6 \%)$ & $0.004^{*}$ \\
\hline Mean number of non-primary sex partners & 2.8 & 2.0 & $0.003 *$ \\
\hline
\end{tabular}

* These are significant

Respondents who had been posted abroad were significantly more likely than others to have had sex with a FSW $(39.1 \%$ vs. $32.8 \%)(\mathrm{p}<0.05)$, less likely to have used a condom during last episode of sex with a FSW $(42.3 \%$ vs. $52 \%)(\mathrm{p}<0.05)$ and more likely to have higher mean number of sexual partners $(2.8$ vs. 2.0$)(\mathrm{p}<0.05)$.

Of the entire sample, $21.3 \%$ agreed that their work conditions had affected their sexual behavior. Among those agreeing, the reported effect was that frequent transfers away from spouse predisposed them to having sex with multiple partners and that stress and tiredness from work affected their sexual performance. When asked how they coped with not having spouse with them during transfers, $32.6 \%$ abstained from sex, $25 \%$ obtained leave to visit spouse, $20 \%$ got new girlfriends, $14.3 \%$ became spiritual, $4.9 \%$ masturbated, $3.2 \%$ used condoms and others participated in sports.

Of the 480 respondents, $23.3 \%$ perceived themselves at some risk of HIV infection, $68.3 \%$ believed they were not at risk at all, and $8.3 \%$ did not answer this question. Of those who perceived themselves to be at risk, $16.1 \%$ estimated the risk to be high, $5.2 \%$ believed the risk was medium and $68.8 \%$ claimed it was low. In response to the question "do you think that you may have been exposed to HIV in the last one year?" a few (12.3\%) affirmed this statement, $83.7 \%$ did not think so and $4 \%$ did not respond to this question.

\section{Context of risky sexual behavior}

The group discussants generally confirmed that unprotected sexual contact with multiple partners including FSW was common among naval personnel as a whole but especially so with ratings. However, they pointed out that this behavior was not peculiar to naval officers. On the contrary, discussants claimed that such practice was also common among long distance drivers, traders, police officers, crew members and business men and women. Discussants also believe that having multiple partners is a tradition that has persisted in the Nigerian navy. As one discussant put it, "there is a common joke that sailors are supposed to have children in each port of visit".
Discussants and informants provided two explanations for this behavior. The first is the nature of military posting which takes many officers away from their families for extended period of time. The second is influence of alcohol. FGD participants and informants believe that participation in risky sexual behavior is an inevitable consequence of use of alcohol. One informant described the connection between transfer, alcohol, and risky sex among naval personnel in this way: "The distance from family, extra cash, a little wine and stress makes it difficult for naval personnel to remain faithful to their spouses or other partners".

Concerning low utilization of condom during sex with FSW, informants said this behavior has persisted because many naval personnel deny that AIDS exists. Some believe that AIDS is a problem affecting only the "oyinbos" (foreigners); others think they are protected from HIV infection if they use traditional medicine. Discussants perceive that the major reason for denial is the fact that the authority is secretive about AIDS-related deaths in the military. As one discussant put it "as officers we often hear that one rating or officer has died of malaria, of tuberculosis but never of AIDS". Discussants believe that until AIDS-related deaths are discussed openly, naval personnel will continue to deny the existence of the virus and participate in risky behaviors.

Informants and discussants identified many deep-seated objections to use of condoms among naval personnel. Such resentments are captured in phrases such as "condom is a strange object", "condom provides half pleasure", and "condom creates a separation between partners". Another explanation for low utilization of the condom is use of alcohol. One informant claimed that naval officers involved in risky sexual behavior are less vigilant because those "under the influence perceive use of any protective device a waste of time."

\section{Suggested interventions}

The discussants and informants suggested four intervention programs that they perceive would reduce risky sexual practices in the navy. The first is sustained education 
using multiple format including drama, video, seminar, targeted at officers on ship and shore. Second, the presentation of statistics of naval personnel affected by HIV may drive the point home that AIDS is real and consequently encourage safe sex. In addition, discussants suggested that persons living with HIV need to be invited to discuss the challenges of living with the virus and thus confirm that AIDS exists. Third, military authority need to promote the condom vigorously and make this product readily available to all who need it. One informant lamented the fact that condoms were not readily available as they were in the past. According to him the "naval tradition is that if you are going out ashore, you are issued condoms and there is no ration about this, however, nowadays due to funding constraints this is no longer practiced". Finally, the military should promote the integrity of the family by discouraging frequent transfer and providing adequate accommodation when transfers are inevitable. Discussants believe that with careful planning there are opportunities for personnel to serve in their places of domicile and thus avoid transfers.

\section{Discussion}

As a group, military personnel are vulnerable to HIV infection due to work conditions, mobility, relatively young age and some ethos of military tradition [10] that favor risky behavior compared to the general population [15]. This makes this group an important target for primary prevention interventions. In this study, the respondents generally had a high level of knowledge of routes of HIV infection. However, some still harbor misconceptions such as the belief that a cure for AIDS is available in Nigeria and that sharing personal items may spread HIV. Similar myths about cure for AIDS have been found in different Nigerian populations including journalists [20], female apprentice tailors [7], and South African military recruits [21]. This misconception may have been fostered in Nigeria because of the tacit support the local media gave to a Nigerian surgeon who claimed to have found a cure for AIDS but would not subject his medication to scientific scrutiny [22]. Unfortunately such misconception may encourage some persons to practice risky behavior by creating the false impression in them that they will be cured if they become infected with HIV.

Despite the relatively good knowledge about sexual transmission of HIV, 33\% of the respondents had sexual contact with a FSW and $46 \%$ did so without using condoms. The proportion of those who had sex with a FSW in this study is less than the $45 \%$ reported among Dutch sailors and Marines during peacekeeping operations in Cambodia [10], but comparable to $48 \%$ among Nigerian military personnel on peace keeping missions abroad [15]. Unprotected sex with a sex worker is a risk factor for HIV infection $[10,17]$ among mobile populations like the military.
Once infected, the individual poses a problem not only to himself but also to his spouse. The risk of HIV infection also threatens the preparedness of the military to carry out its functions [15]. Another source of concern is the high proportion $(88 \%)$ of respondents who reported having multiple partners. However, this number is higher than $75 \%$ found among the Nigerian police officers [18].

Frequent transfer away from the family for extended period of time is a key feature of military service. According to the Joint United Nations Program on AIDS, frequent transfer is the single most important risk factor for acquiring and spreading HIV to others within the military [10]. In this study, 92\% of respondents had experienced at least one transfer with the majority not having the opportunity to take their spouses with them. Apart from the emotional stress this places on individuals, frequent transfers favor sexual contact with FSW. Although frequent transfer and separation from families favor participation in risky sexual behavior in the military as a whole, those posted abroad for training and peace keeping operations are particularly vulnerable because they had participated more in risky sexual behaviors than their counterparts who experienced only local transfers. There are two possible explanations for this behavior. One, personnel sent abroad are generally better paid, have more financial resources than their colleagues stationed at home and are therefore better able to buy sexual services from the local population. Two, although officers working in the country can arrange to travel to visit families at short notices, officers sent abroad do not have such opportunity, yet they experience greater tension and more likely to resort to risky sexual behavior. These behaviors have serious implications for rapid spread of HIV because when local residents or troops themselves are infected with HIV, the presence of military personnel who have multiple sex partners enable HIV run quickly through the existing sexual networks in communities, multiplying the infection rate exponentially [10].

Seventy seven percent of the sample believed that they were not at risk at all of contracting HIV. This figure is comparable to the 2003 National HIV/AIDS and Reproductive Health Survey which reported $72 \%$ in the civilian population [23]. This low perception of risk is probably influenced by the widespread denial of the existence of HIV in the country. Many citizens claim they do not believe AIDS exists in the country because they have not personally seen anyone infected with the disease, others perceive the dangers posed by AIDS with fatalism arguing that a person who is not killed by AIDS will eventually "die of something else anyway" [5]. 


\section{Implications for interventions}

Military service presents a unique opportunity in which HIV/AIDS prevention interventions are targeted to a "large captive audience" in a highly organized fashion [10]. The qualitative data have provided valuable clues of feasible primary interventions in this population. The Nigerian Naval authority need to urgently embark on sustained STD and HIV educational program among naval personnel and their families in the barracks and in schools to reinforce safe sexual behaviors [15]. The program should emphasize reduction in number of sexual partners and consistent use of condoms. This effort should also focus on changing naval personnel's perception of risk. The presentation of relevant data on the proportion of those affected must also be seen as part of the package of credible educational program. However, naval personnel living with HIV must be assured of the confidentiality of their condition.

Secondly, there is the need for an aggressive promotion of the consistent and correct use of condoms targeted at the entire naval population, with an emphasis on personnel on peace keeping operation. It is particularly important that personnel on peace keeping operations be provided with constant supply of condoms to motivate them to use these products. As the experience from Thailand shows, STI/HIV infections rates can be reduced substantially in the military with active promotion of condoms [24]. Women involved in sex work in areas where naval units are stationed must also be included in condom promotion activities as part of a comprehensive package to promote safe sexual behavior. To this end, it is recommended that such women be provided with female condom, a product over which they can exercise some control. Given the current exorbitant cost of female condom in Nigeria, the cost of this product must be subsidized to encourage women to fully utilize it.

Finally, there is need for a revision of the policy of frequent transfers. A new policy that emphasizes maintenance of family life and shortening tours of duty away from home, and finding ways of helping soldiers to bring their families with them if long term posting are not avoidable is recommended.

This study has two limitations. First, the findings may not be generalized to all naval personnel in Nigeria since the sample was selected from only one out of the three naval commands in the country. Additional studies with larger sample size covering all naval locations are required to address this constraint. Secondly, although women are increasingly being involved in military operations [25] we were not able to make meaningful gender comparisons because of the relatively small females in this study. Future studies on risky behaviors in the military should focus more on the female population in order to determine the extent to which females in the Nigerian military are vulnerable to HIV infection.

\section{Conclusion}

The growing epidemic of HIV requires targeted interventions at populations at risk of infection. This study of the Nigerian naval population in Lagos has confirmed that many in this group have participated in behaviors that elevate their risk of exposure to HIV infection. Since naval personnel live and interact freely with civilian population they represent a potential bridging group for disseminating HIV into the larger population. The organizational structure of the navy provides an excellent opportunity to implement interventions that will enable the men and women in military service reduce their chances of exposure to HIV.

\section{Competing interests}

None declared.

\section{Author's contributions}

UAN developed draft instruments, pre-tested survey instruments, conducted interviews, discussions, wrote drafts of findings. AJA conceived of the study and participated in its design and coordination and wrote the draft manuscript. All authors read and approved of final manuscript.

\section{Acknowledgements}

We appreciate the helpful comments of Drs. Peter Lurie and Suzanne Maman on an earlier draft of this paper. We also thank all respondents who participated in the study and appreciate the efforts of Mr. Dele Oladoja who analyzed the data. We are grateful to the authorities of the naval command in Lagos who provided official approval for this study.

\section{References}

I. Federal Ministry of Health: HIV sero-prevalence survey in Nigeria. Lagos, Nigeria; 1995.

2. Federal Ministry of Health: HIV/Syphilis Sero-Prevalence Survey in Nigeria. 1999.

3. The Joint United Nations Program on AIDS: Fact Sheet Effects of HIVAIDS in Sub Saharan Africa. 2002.

4. The Joint United Nations Program on AIDS: Epidemiological fact sheet on HIVIAIDS and sexually transmitted infections in Nigeria. 2000.

5. Alubo O: Breaking the wall of silence: AIDS policy and politics in Nigeria. Inter J Health Serv 2002, 32(3):55I-556.

6. Iwuagwu S, Ajuwon AJ, Olaseha IO: Sexual behavior and negotiation of male condom by female students of University of Ibadan, Nigeria. J Obste Gyn 2000, 20(5):507-5I 3.

7. Ajuwon AJ, McFarland W, Hudes E, Adedapo S, Okikiolu T, Lurie P: Risk-Related Behavior, Sexual Coercion and implications for Prevention strategies among Female Apprentice Tailors, Ibadan, Nigeria. AIDS and Behav 2002, 6(3):233-234.

8. Eromonsele SA: Perceived susceptibility to HIVIAIDS and pattern of condom use among female sex workers in two cities in Osun state, Nigeria. MPH Dissertation of the University of Ibadan, Nigeria 2002.

9. Akintola O: Knowledge about AIDS and risky sexual behavior of commercial drivers in Ibadan. MPH Dissertation of the University of Ibadan, Nigeria 2000. 
10. Joint United Nations Program on AIDS: AIDS and the Military. Best practice collection 1998.

II. Nwosu S: HIVIAIDS and the military. The Airmen Journal of Nigerian Air Force . 1999, 4, October

12. Noah D, Fidas G: The global infectious disease and its implications for the United States. Washington DC, National Intelligence Council; 2000.

13. Department of Defense and The Joint United Nations Program on AIDS: Naval Health Research Centre San Diego California; 200I.

14. Fleshman : AIDS Prevention in the ranks. Africa Recovery 200I, I5(I-2):16-8.

15. Adebajo SB, Mafeni J, Moreland S, Murray N: Knowledge, attitudes, and sexual behavior among Nigerian military concerning HIVIAIDS and STD. Final Technical Report by Policy Project/ Nigeria 2002.

16. United States Bureau of the Census, Population Division: International Programs Center HIVIAIDS surveillance data 1998.

17. Celentano DD, Nelson KE, Supraset S, Eiumtrakal S, Julvatana S, Kuntolbutra S, Akarasewi P, Mantanasavawoot A, Wright NH, Sirisopana $\mathrm{N}$ : Risk factors for HIV-I Seroconversion among men in Northern Thailand. JAMA 1996, 275(2): 122-7.

18. Akinawo EO: Sexual networking STD's and HIVIAIDS transmission among Nigerian Police officers. Health Tran Rev 1995, 5(supplement):

19. Raufu A: AIDS scare hits Nigerian military. AIDS Analysis Africa 2002. February-march

20. Isibor D: Knowledge about AIDS and attitude towards people living with HIV among journalists in Ibadan, Nigeria. MPH dissertation of the University of Ibadan, Nigeria 2003.

21. Ver der Ryst E, Joubert G, Steyn F, Heunis C, le Roux J, Williamson C: HIVIAIDS- related knowledge, attitudes and practices among South African military recruits. S A Med J 200I, 9I(7):58I-59I.

22. The Punch Newspaper: AIDS Infects $\mathbf{0 . 8}$ million Lagosians. :5. $2001,3^{\text {rd }}$ May

23. Federal Ministry of Health: National HIVIAIDS and Reproductive Health Survey. Federal Ministry of Health, Abuja, Nigeria; 2003.

24. Celetano DD, Nelson KE, Suprasert S, Eiumtakul S, Julvanata S, Kuntolbutra S, Akarasewi P, Mantanasavawoot A, Wright NH, Sirisopana $\mathrm{N}$ : Decreasing incidence of HIV and sexually transmitted diseases in Young Thai men: evidence of success of the HIVI AIDS control prevention program. AIDS 1998, I2(5):29-36.

25. Abel E: Sexual risk behaviors among ship and shore based navy women. Military Medicine 1998, 163(4):250-6.

\section{Pre-publication history}

The pre-publication history for this paper can be accessed here:

http://www.biomedcentral.com/1471-2458/4/24/prepub
Publish with Biomed Central and every scientist can read your work free of charge

"BioMed Central will be the most significant development for disseminating the results of biomedical research in our lifetime. "

Sir Paul Nurse, Cancer Research UK

Your research papers will be:

- available free of charge to the entire biomedical community

- peer reviewed and published immediately upon acceptance

- cited in PubMed and archived on PubMed Central

- yours - you keep the copyright 